\title{
Analisis Manajemen Risiko Terhadap Aspek Keselamatan dan Kesehatan Kerja Pada Pembangunan Daerah Irigasi (Lanjutan) di Tarusan Pada Titik P-52 Dan P-92
}

\section{Wendi Boy ${ }^{1}$, Rodiah Tulhija M $^{2}$ dan Ridho Aidil Fitrah ${ }^{3}$}
1) Prodi Teknik Sipil Universitas Dharma Andalas Padang Sumatera Barat. email: wendi@unidha.ac.id
2) Prodi Teknik Sipil Universitas Dharma Andalas Padang Sumatera Barat, email: rodiahtulhija99@gmail.com
3) Jurusan Teknik Sipil Universitas Andalas Padang Sumatera Barat, email: ridho.af@unand.ac.id

\section{$\underline{\text { Info Artikel }}$ \\ Riwayat Artikel:}

Dikirim :08-01-2022

Direvisi :24-01-2022

Diterima :26-01-2022

Keywords :

Kesehatan dan

keselamatan Kerja

(K3), Manajemen

Risiko, Kecelakaan

Kerja, Identifikasi

Risiko

\begin{abstract}
Dalam pelaksanaan proyek konstruksi selalu ada potensi bahaya atau risiko yang dapat menyebabkan kerugian. Setiap tempat kerja selalu memiliki risiko kecelakan kerja yang dapat menggangu aktivitas pekerjaan dalam proyek. Oleh karena itu diperlukan suatu manajemen agar dapat mengatur jalannya proyek dengan baik, termasuk Manajemen Risiko Kesehatan dan Keselamat Kerja (K3). Tujuan dan sasaran Manajemen Risiko K3 adalah terciptanya sistem K3 di tempat kerja melibatkan segala pihak sehingga dapat mencegah dan mengurangi kecelakaan dan penyakit akibat kerja dan terciptanya tempat kerja yang aman, efisien, dan produktif. Penelitian ini bertujuan untuk mengidentifikasi risiko $\mathrm{K} 3$, penilaian risiko $\mathrm{K} 3$, serta strategi pengendalian terhadap risiko K3 pada pekerjaan Pembangunan Daerah Irigasi Kawasan Sawah Laweh Tarusan di Kab. Pesisir Selatan (Paket I) Lanjutan. Dari hasil penelitian teridentifikasi 45 potensi risiko kecelakaan kerja yang dapat terjadi. Berdasarkan penilaian terhadap Risiko K3 diketahui level masing-masing risiko yaitu terdapat 45 risiko tergolong Medium Risk dan dari 47 mengidentifikasi risiko terdapat 2 tergolong Low Risk. Pada penelitian ini perlu dilakukan penanganan yaitu dengan memberikan pengendalian risiko berupa penerapan K3 di lapangan meliputi penggunaan APD, rambu-rambu peringatan dan standarisasi pengaman pada saat bekerja di lapangan.
\end{abstract}

\section{PENDAHULUAN}

Pemerintah Indonesia saat ini mulai melakukan pembangunan dengan pesat di segala bidang terutama dalam bidang konstruksi baik di kota besar maupun di kota kecil. Pembangunan konstruksi meliputi: fasilitas masyarakat pada umumnya seperti bangunan pemerintahan, sekolah, rumah sakit jembatan, irigasi, jalan dan lain sebagainya (Sepang et al, 2013; Hakim, 2020).
Proyek konstruksi memiliki risiko yang tinggi akan terjadinya kecelakaan kerja. Hal tersebut dipengaruhi beberapa faktor yaitu kondisi fisik dan area proyek yang terbuka seperti iklim, cuaca, dan lingkungan. Menurut ILO (International Labour Organization) (2013), terdapat 3 faktor penyebab terjadinya kecelakaan kerja adalah faktor manusia, faktor pekerjaan dan faktor lingkungan di tempat kerja. 
Faktor manusia meliputi: umur, tingkat pendidikan dan pengalaman kerja. Sedangkan untuk faktor lingkungan berupa lingkungan fisik (pencahayaan dan kebisingan), lingkungan kimia dan faktor lingkungan biologi (OHSAS 18001: 2007).

Pada BPJS Ketenagakerjaan menyatakan bahwa pada tahun 2020 kasus kecelakaan kerja mencapai 153.044, angka tersebut mengalami penurunan tipis sebanyak 1,46 persen dari data kecelakaan kerja di tahun 2019 sebanyak 155.327 kasus (Laporan BPJS Ketenagakerjaan 2020). Dari data tersebut terlihat bahwa keselamatan dan kesehatan kerja mulai diterapkan, tetapi dalam pelaksanaannya masih terdapat pekerja yang mengabaikan aspek K3 salah satunya yaitu penggunaan alat pelindung diri, dari aspek tersebut kemungkinan besar juga terjadi pada aspek yang lainnya. (Rethyna, 2018).

Beberapa risiko yang tinggi pada proyek di ketinggian adalah terjatuh, tergores, terpeleset, terbentur dan kejatuhan material (Setianingrum, 2012; Wardhana, 2018). Sedangkan risiko lainnya adalah Sling dari bore pile putus, Tertimpa stock material batu, tergores ujung besi cor, tertimpa benda berat, kena benda tajam, kena ledakan (Wibisono, 2016).

Upaya untuk mengelola risiko K3 ialah dengan cara melakukan manajemen Risiko yang bertujuan untuk mencegah terjadinya kecelakaan yang tidak dinginkan secara komprehensif, terencana dan terstruktur (Ramli, 2010). Istilah risiko (risk) memiliki banyak definisi, tetapi pengertian secara ilmiah sampai saat ini masih tetap beragam, menurut kamus bahasa Indonesia dalam buku Manajemen Risiko Bisnis (Pramana, 2011), risiko adalah akibat yang kurang menyenangkan, merugikan, membahayakan dari suatu perbuatan atau tindakan, dengan kata lain risiko merupakan kemungkinan situasi atau keadaan yang dapat mengancam pencapaian tujuan serta sasaran sebuah organisasi atau individu (Pramana, 2011).

Suma'mur ,1981 (dalam Trianty, 2014) jenisjenis pekerjaan mempunyai peranan besar dalam menentukan jumlah dan macam kecelakaan. Beberapa jenis pekerjaan dalam sebuah proyek konstruksi bangunan menyertakan risiko atas terjadinya beberapa kecelakaan yang berulang kali menunjukkan frekuensi kecelakaan kerja fatal yang lebih tinggi.

\section{METODE PENELITIAN} digunakan

Pada analisa manajemen risiko ini

1. Studi Pustaka: Pengkajian jurnal-jurnal, penelitian terdahulu dan buku yang didapat untuk penentuan variabel risiko.

2. Pengumpulan data

Kriteria data dalam analisis manajemen pada penelitian ini adalah:

a. Data Primer:

- Wawancara

- Kuisioner

b. Data Sekunder:

- Struktur Organisasi

c. Uji Validitas, Uji Reliabilitas (cronbach alpha)

d. Analisa data dengan matriks risiko

\section{HASIL DAN PEMBAHASAN}

\section{Data Umum Lokasi Penelitian}

Penelitian ini berdasarkan data yang diperoleh serta hasil observasi lapangan yaitu dengan cara menyebar kuesioner kepada responden yang sudah berpengalaman dalam hal K3 bangunan Jaringan DI. Kawasan Sawah Laweh Tarusan di Kab. Pesisir Selatan (Paket I) Lanjutan di P-59 dan P-92, yang selanjutnya diolah berdasarkan teori-teori dari tinjauan kepustakaan.

\section{Struktur Organisasi Proyek}

Struktur organisasi merupakan suatu badan yang menggambarkan jabatan atau kedudukan dari suatu kerja atau jabatan yang tertinggi sampai pada yang terendah, sedangkan organisasi itu memiliki tujuan yang akan dicapai melalui kerjasama sekelompok orang-orang yang terlibat didalamnya.

Hasil dari kegiatan pengorganisasian adalah terciptanya organisasi yang dapat digerakkan sebagai satu kesatuan yang bulat dalam rangka usaha pencapaian tujuan yang telah ditetapkan sesuai dengan tugas pokok dan fungsi serta yang telah diwadahkan dalam satu susunan organisasi yang sesuai dengan kebutuhan organisasi yang bersangkutan. Sukses atau tidaknya suatu perusahaan akan sangat tergantung pada fungsi manajemennya dan fungsi administrasi dalam melaksanakan fungsi organisasi dapat dilihat dan dinilai dari kemampuan untuk menciptakan organisasi yang baik. 
Begitu juga yang telah dilaksanakan PT. Gunung Tabor, dalam usahanya mencapai tujuan perusahaan tersebut, supaya karyawannya bekerja pada perusahaannya dengan jelas akan tugas dan tanggung jawabnya serta kepada siapa dia harus memberikan wewenangnya, maka PT. Gunung Tabor Perkasa membuat struktur organisasi proyek Pembangunan Jaringan DI. Kawasan Sawah Laweh Tarusan di Kab. Pesisir Selatan (Paket I) Lanjutan. Untuk lebih jelasnya bisa dilihat pada struktur organisasi Pembangunan Jaringan DI. Kawasan Sawah Laweh Tarusan di Kab. Pesisir Selatan (Paket I) Lanjutan PT. Gunung Tabor yang tergambar dalam Gambar 1 dibawah ini:

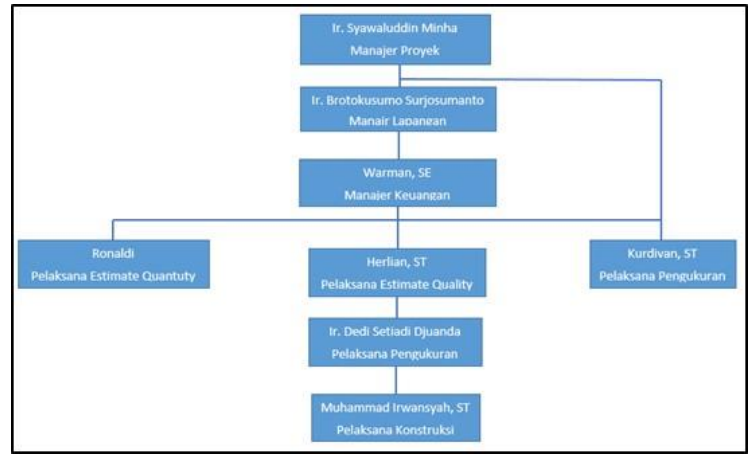

Gambar 1. Struktur Organisasi Proyek (sumber: Data Proyek 2021)

\section{Data Responden Penelitian}

Data diperoleh dari hasil wawancara dan penyebaran kuesioner pada beberapa staf minimal setingkat pengawas. Pada penelitian ini kuesioner diberikan kepada 10 orang responden. Berikut data responden berdasarkan usia, pengalaman kerja, tingkat pendidikan, dan jabatan yang disajikan dalam bentuk diagram.

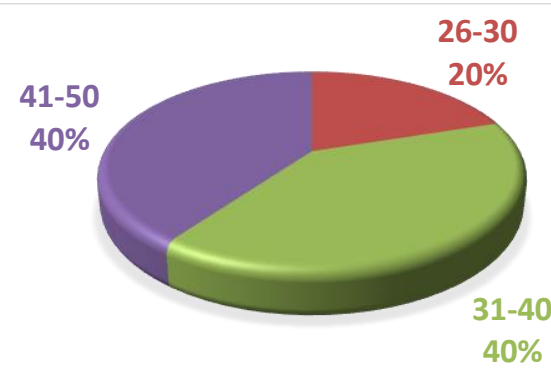

Gambar 2. Diagram Usia Responden

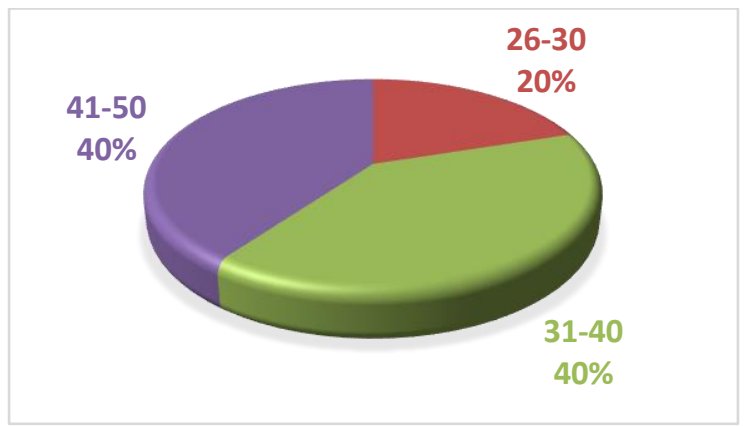

Gambar 2. Diagram Usia Responden

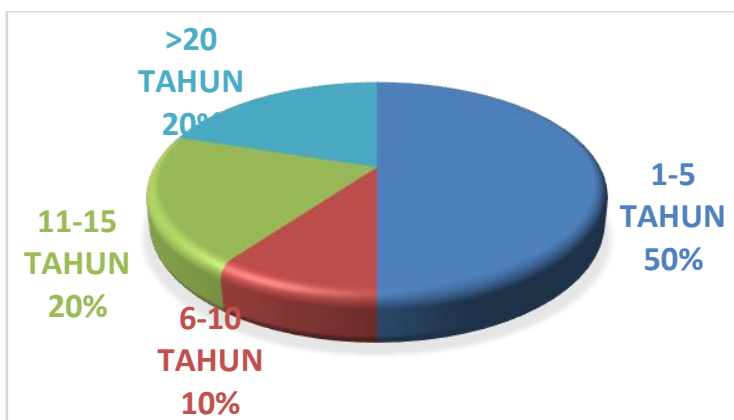

Gambar 3. Diagram Pengalaman Kerja Responden

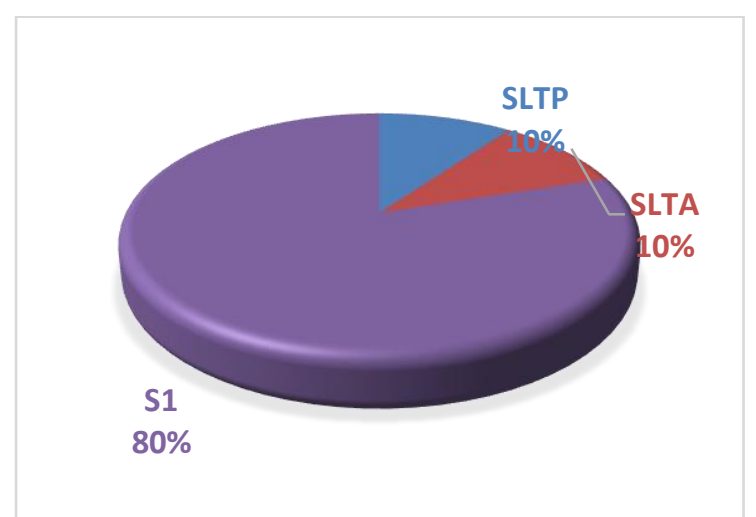

Gambar 4. Diagram Tingkat Pendidikan Responden

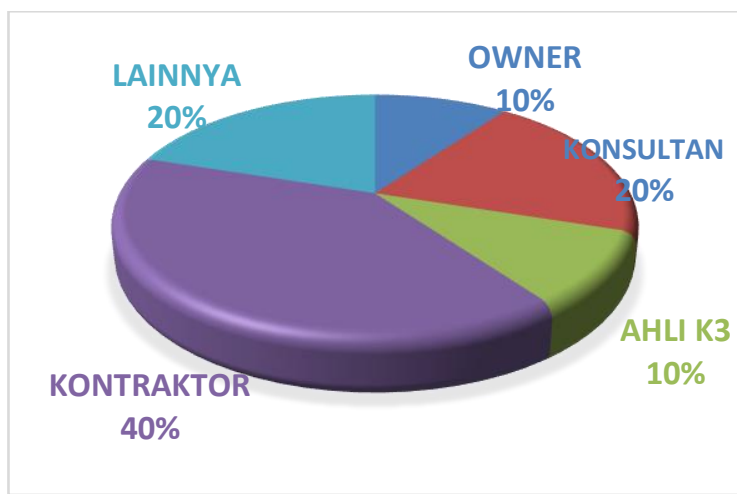

Gambar 5. Diagram Jabatan Responden

Setelah didapat variabel risiko K3 yang mungkin terjadi pada proyek, dilakukan survey melalui kuesioner mengenai dampak dan 
kemungkinan terjadinya risiko K3. Proses ini dilakukan dengan membagikan form kuesioner kepada responden dengan didampingi peneliti. Setelah dilakukan penyebaran kuesioner jawaban responden tersebut diuji validitas dan reliabilitasnya. Pengujian tersebut dilakukan dengan bantuan program SPSS versi 28 .

\section{Uji validitas dan Uji reliabilitas}

Uji validitas bertujuan untuk mengukur ketepatan atau kecermatan instrumen yang digunakan dalam suatu penelitian atau untuk melihat apakah hasil pengisian kuesioner yang dilakukan telah valid dan dimengerti oleh responden. Dalam Penelitian ini sampel yang digunakan sebanyak 10 sampel responden dengan taraf signifikan 5\% sehingga nilai $\mathrm{R}$ yang didapat yaitu 0,6319. Dari hasil uji validitas nilai $\mathrm{r}$ Hitung > $\mathrm{r}$ Tabel 0,6319 sehingga hasil pengisian kuesioner didapatkan 36 variabel risiko yang valid dari 54 variabel risiko. Hasil pengujian validitas dapat dilihat pada Tabel 1 dibawah ini.

Tabel 1. Hasil Pengujian Validitas

\begin{tabular}{|c|c|c|c|c|}
\hline \multirow[b]{2}{*}{ Kegiatan } & \multirow[b]{2}{*}{ Variabel Risiko } & \multicolumn{3}{|c|}{ Uji Validitas } \\
\hline & & $\begin{array}{c}\mathrm{R} \\
\text { Hitung }\end{array}$ & $\begin{array}{c}\mathrm{R} \\
\text { Tabel }\end{array}$ & Keterangan \\
\hline \multirow{6}{*}{$\begin{array}{c}\text { Proses } \\
\text { pemotongan } \\
\text { besi (X1) }\end{array}$} & Tangan pekerja tergores besi (X1.1) & 0,413 & 0,6319 & Tidak Valid \\
\hline & Tangan pekerja tergores besi (X1.1) & 0,399 & 0,6319 & Tidak Valid \\
\hline & Tangan pekerja tertusuk besi (X1.3) & 0,599 & 0,6319 & Tidak Valid \\
\hline & $\begin{array}{l}\text { Tangan pekerja terkena bar cutter atau bar bar bender } \\
(X 1.4)\end{array}$ & $.845^{* *}$ & 0,6319 & Valid \\
\hline & $\begin{array}{l}\text { Terpapar Kebisingan saat memotong besi dengan } \\
\text { menggunakan mesin bar cutter }(X 1.5)\end{array}$ & 0,111 & 0,6319 & Tidak Valid \\
\hline & Mata pekerja terkena percikan api (X1.6) & 0,207 & 0,6319 & Tidak Valid \\
\hline \multirow{5}{*}{$\begin{array}{c}\text { Proses } \\
\text { pemindahan } \\
\text { besi ke area } \\
\text { kerja }(\mathrm{X} 2)\end{array}$} & Tangan pekerja tertusuk besi (X2.1) & 0,359 & 0,6319 & Tidak Valid \\
\hline & Tangan pekerja tergores besi (X2.2) & 0,461 & 0,6319 & Tidak Valid \\
\hline & Tangan pekerja terjepit besi (X2.3) & 0,142 & 0,6319 & Tidak Valid \\
\hline & Kaki pekerja tertimpa besi (X2.4) & 0,302 & 0,6319 & Tidak Valid \\
\hline & Pekerja dibawah kejatuhan material besi (X2.5) & 0,457 & 0,6319 & Tidak Valid \\
\hline \multirow{6}{*}{$\begin{array}{l}\text { Proses } \\
\text { pembesian } \\
\quad(\mathrm{X} 3)\end{array}$} & Pekerja Terjatuh dari Ketinggian (X3.1) & 0,609 & 0,6319 & Tidak Valid \\
\hline & Pekerja Tertusuk kawat bendrat (X3.2) & 0,376 & 0,6319 & Tidak Valid \\
\hline & Tangan pekerja tergores besi (X3.3) & $-0,125$ & 0,6319 & Tidak Valid \\
\hline & Tangan pekerja terjepit besi (X3.4) & 0,216 & 0,6319 & Valid \\
\hline & Tangan pekerja tertusuk besi (X3.5) & 0,404 & 0,6319 & Tidak Valid \\
\hline & Kaki pekerja terkena ujung besi (X3.6) & 0,605 & 0,6319 & Tidak Valid \\
\hline \multirow{6}{*}{$\begin{array}{l}\text { Pemasangan } \\
\text { Bekisiting } \\
\text { (dinding } \\
\text { saluran \& plat } \\
\text { lantai) (X4) }\end{array}$} & Pekerja tertimpa bekisting (X4.1) & $.727^{*}$ & 0,6319 & Valid \\
\hline & Tangan pekerja tertusuk material (paku/kayu) (X4.2) & 0,543 & 0,6319 & Tidak Valid \\
\hline & Tangan pekerja terkena palu (X4.3) & 0,480 & 0,6319 & Tidak Valid \\
\hline & Tangan pekerja terjepit saat penempatan bekisting (X4.4) & 0,484 & 0,6319 & Tidak Valid \\
\hline & Kaki pekerja terjepit saat penempatan bekisting (X4.5) & 0,594 & 0,6319 & Tidak Valid \\
\hline & $\begin{array}{l}\text { Pekerja Terjatuh dari ketinggian saat pemasangan } \\
\text { bekisting (X4.6) }\end{array}$ & $.709^{*}$ & 0,6319 & Valid \\
\hline \multirow{5}{*}{$\begin{array}{l}\text { Pembongkaran } \\
\text { Bekisiting } \\
\text { (plat lantai, } \\
\text { dinding } \\
\text { saluran) (X5) }\end{array}$} & $\begin{array}{l}\text { Pekerja Terjatuh dari ketinggian saat pembongkaran } \\
\text { bekisting (X5.1) }\end{array}$ & $.698^{*}$ & 0,6319 & Valid \\
\hline & Tangan pekerja tertusuk material (paku/kayu) (X5.2) & 0,563 & 0,6319 & Tidak Valid \\
\hline & Tangan pekerja terkena palu (X5.3) & 0,090 & 0,6319 & Tidak Valid \\
\hline & Kaki pekerja kejatuhan alat (X5.4) & 0,406 & 0,6319 & Tidak Valid \\
\hline & Pekerja tertimpa bekisting (X5.5) & $.881^{* *}$ & 0,6319 & Valid \\
\hline \multirow{4}{*}{$\begin{array}{l}\text { Pemasangan } \\
\text { dan pembong- } \\
\text { karan scafol- } \\
\text { ding }(X 6)\end{array}$} & Pekerja jatuh dari ketinggian (X6.1) & $.642^{*}$ & 0,6319 & Valid \\
\hline & $\begin{array}{l}\text { Scaffolding jatuh/roboh dan menimpa Pekerja atau fasilitas } \\
\text { (X6.2) }\end{array}$ & $.797^{* *}$ & 0,6319 & Valid \\
\hline & Pekerja yang dibawah tertimpa Material (X6.3) & $.701^{*}$ & 0,6319 & Valid \\
\hline & $\begin{array}{l}\text { Mata pekerja terkena adonan beton saat menuangkan } \\
\text { adonan beton ready mix ke cetakan) (X7.1) }\end{array}$ & 0,564 & 0,6319 & Tidak Valid \\
\hline
\end{tabular}




\begin{tabular}{|c|c|c|c|c|}
\hline \multirow[b]{2}{*}{ Kegiatan } & \multirow[b]{2}{*}{ Variabel Risiko } & \multicolumn{3}{|c|}{ Uji Validitas } \\
\hline & & $\begin{array}{c}\mathrm{R} \\
\text { Hitung }\end{array}$ & $\begin{array}{c}\mathrm{R} \\
\text { Tabel }\end{array}$ & Keterangan \\
\hline \multirow{7}{*}{$\begin{array}{c}\text { Proses } \\
\text { Pengecoran } \\
\text { (X7) }\end{array}$} & pekerja terjatuh dari ketinggian (X7.2) & $.676^{*}$ & 0,6319 & Valid \\
\hline & $\begin{array}{l}\text { Pekerja terpeleset saat menahan/memindahkan concrete } \\
\text { bucket (X7.3) }\end{array}$ & $.685^{*}$ & 0,6319 & Valid \\
\hline & Kabel Sling Putus (X7.4) & $.830^{* *}$ & 0,6319 & Valid \\
\hline & Pekerja tertimpa concrete bucket (X7.5) & $.780^{* *}$ & 0,6319 & Valid \\
\hline & Luka Gores (Akibat Concrete Vibrator) (X7.6) & $.707^{*}$ & 0,6319 & Valid \\
\hline & Lepasnya pipa trime $(X 7.7)$ & $.717^{*}$ & 0,6319 & Valid \\
\hline & Robohnya cetakan beton (X7.8) & $-0,016$ & 0,6319 & Tidak Valid \\
\hline \multirow{3}{*}{$\begin{array}{c}\text { Proses metoda } \\
\text { Predrainage } \\
(X 8)\end{array}$} & Pekerja/Alat terseret aliran sungai (X8.1) & $.677^{*}$ & 0,6319 & Valid \\
\hline & Pekerja terjatuh dari ketingian & 0,314 & 0,6319 & Tidak Valid \\
\hline & Pekerja / Alat terjebak lumpur (X8.3) & 0,471 & 0,6319 & Tidak Valid \\
\hline \multirow{5}{*}{$\begin{array}{c}\text { Proses } \\
\text { Pemasangan } \\
\text { box culvert } \\
\text { (X9) }\end{array}$} & $\begin{array}{l}\text { Pekerja terluka akibat terkena kayu atau benda berbahaya } \\
\text { di air (kayu, ranting, batu) (X9.1) }\end{array}$ & $.815^{* *}$ & 0,6319 & Valid \\
\hline & pekerja tersengat listrik (X9.2) & $.749^{*}$ & 0,6319 & Valid \\
\hline & Pekerja terkena material (X9.3) & $.716^{*}$ & 0,6319 & Valid \\
\hline & Gangguan Pernafasan akibat debu Proyek(X9.4) & 0,574 & 0,6319 & Tidak Valid \\
\hline & kebisingan saat penggunaan mesin di proyekl (X9.5) & 0,470 & 0,6319 & Tidak Valid \\
\hline
\end{tabular}

Uji reliabilitas, untuk mengetahui suatu instrumen dinyatakan reliabilitas, menurut Sugiyono (2012) mengemukakan bahwa: "Suatu instrumen dinyatakan reliabel, bila koefisien reliabilitas minimal 0.60 ". Berdasarkan pendapat tersebut, maka dapat diketahui bahwa suatu instrumen dinyatakan reliabel jika nilai Alpha $\geq$ 0.60 , Dari hasil uji reliabilitas nilai $\mathrm{r}$ Hitung > Alfa 0,6 sehingga dinyatakan memiliki reliabilitas yang tinggi. Hasil pengujian didapatkan nilai reliabilitas Cronbach Alpha sebesar 0,942 lebih besar dari 0,6 maka data pengujian dikatakan reliabel sebagaimana dapat dilihat pada Tabel 2.

Tabel 2. Hasil Pengujian Reliabilitas

Reliability Statistics

\begin{tabular}{ll}
\hline Cronbach's Alpha & $\mathrm{N}$ of Items \\
\hline 0.942 & 47
\end{tabular}

\section{Analisa data dengan matriks risiko}

Setelah nilai indeks risiko diperoleh, maka langkah selanjutnya adalah penggolongan level risiko berdasarkan matriks risiko AS/NZS 4360. Berikut ini merupakan tabel matriks analisa risiko menurut AS/NZS 4360:2004 dalam Boy et al, 2021).

Tabel 3. Matriks Analisa Risiko (Level)

\begin{tabular}{|c|c|c|}
\hline Nilai Risiko & Kategori Risiko & Keterangan \\
\hline $1-3$ & $\mathrm{~L}$ & Low \\
\hline $4-9$ & $\mathrm{M}$ & Moderate \\
\hline $10-16$ & $\mathrm{H}$ & High \\
\hline $17-25$ & $\mathrm{VH}$ & Very High \\
\hline
\end{tabular}

Hasil peringkat risiko dapat dilihat pada tabel Tabel 4 berikut ini merupakan tabel hasil peringkat risiko berdasarkan Matriks Risiko AS/NZS 4360.

Tabel 4. Hasil Peringkat Risiko Berdasarkan Matriks Risiko AS/NZS 4360

\begin{tabular}{|c|c|c|c|}
\hline No & Kegiatan & Variabel Risiko & $\begin{array}{l}\text { Nilai } \\
\text { Risiko }\end{array}$ \\
\hline \multirow{6}{*}{1} & \multirow{6}{*}{$\begin{array}{l}\text { Proses } \\
\text { pemotongan besi } \\
(\mathrm{X} 1)\end{array}$} & Tangan pekerja tergores besi (X1.1) & 5.4 \\
\hline & & Tangan pekerja tergores besi (X1.1) & 5.6 \\
\hline & & Tangan pekerja tertusuk besi (X1.3) & 5.8 \\
\hline & & Tangan pekerja terkena bar cutter atau bar bar bender $(X 1.4)$ & 6.6 \\
\hline & & $\begin{array}{l}\text { Terpapar Kebisingan saat memotong besi dengan menggunakan mesin } \\
\text { bar cutter }(X 1.5)\end{array}$ & 7.4 \\
\hline & & Mata pekerja terkena percikan api (X1.6) & 5.7 \\
\hline 2 & & Tangan pekerja tertusuk besi (X2.1) & 5.9 \\
\hline
\end{tabular}




\begin{tabular}{|c|c|c|c|}
\hline No & Kegiatan & Variabel Risiko & $\begin{array}{l}\text { Nilai } \\
\text { Risiko }\end{array}$ \\
\hline & \multirow{4}{*}{$\begin{array}{l}\text { Proses } \\
\text { pemindahan besi } \\
\text { ke area kerja (X2) }\end{array}$} & Tangan pekerja tergores besi (X2.2) & 6.5 \\
\hline & & Tangan pekerja terjepit besi (X2.3) & 4.7 \\
\hline & & Kaki pekerja tertimpa besi (X2.4) & 6.6 \\
\hline & & Pekerja dibawah kejatuhan material besi (X2.5) & 5.2 \\
\hline \multirow{6}{*}{3} & \multirow{6}{*}{$\begin{array}{l}\text { Proses pembesian } \\
\text { (X3) }\end{array}$} & Pekerja Terjatuh dari Ketinggian (X3.1) & 3.7 \\
\hline & & Pekerja Tertusuk kawat bendrat (X3.2) & 4.4 \\
\hline & & Tangan pekerja tergores besi (X3.3) & 6.4 \\
\hline & & Tangan pekerja terjepit besi (X3.4) & 5.3 \\
\hline & & Tangan pekerja tertusuk besi (X3.5) & 7.2 \\
\hline & & Kaki pekerja terkena ujung besi (X3.6) & 5.5 \\
\hline \multirow{6}{*}{4} & \multirow{6}{*}{$\begin{array}{l}\text { Pemasangan } \\
\text { Bekisiting } \\
\text { (dinding saluran } \\
\text { \& plat lantai) } \\
\text { (X4) }\end{array}$} & Pekerja tertimpa bekisting (X4.1) & 6.4 \\
\hline & & Tangan pekerja tertusuk material (paku/kayu) (X4.2) & 6.4 \\
\hline & & Tangan pekerja terkena palu (X4.3) & 5.6 \\
\hline & & Tangan pekerja terjepit saat penempatan bekisting (X4.4) & 6.2 \\
\hline & & Kaki pekerja terjepit saat penempatan bekisting (X4.5) & 6 \\
\hline & & Pekerja Terjatuh dari ketinggian saat pemasangan bekisting (X4.6) & 6.4 \\
\hline \multirow{5}{*}{5} & \multirow{5}{*}{$\begin{array}{l}\text { Pembongkaran } \\
\text { Bekisiting (plat } \\
\text { lantai, dinding } \\
\text { saluran) (X5) }\end{array}$} & Pekerja Terjatuh dari ketinggian saat pembongkaran bekisting (X5.1) & 3 \\
\hline & & Tangan pekerja tertusuk material (paku/kayu) (X5.2) & 5 \\
\hline & & Tangan pekerja terkena palu (X5.3) & 5.9 \\
\hline & & Kaki pekerja kejatuhan alat (X5.4) & 5.2 \\
\hline & & Pekerja tertimpa bekisting (X5.5) & 5.5 \\
\hline \multirow{3}{*}{6} & \multirow{3}{*}{$\begin{array}{l}\text { Pemasangan dan } \\
\text { pembongkaran } \\
\text { scafolding }(X 6) \\
\end{array}$} & Pekerja jatuh dari ketinggian (X6.1) & 8.3 \\
\hline & & Scaffolding jatuh/roboh dan menimpa Pekerja atau fasilitas (X6.2) & 6.2 \\
\hline & & Pekerja yang dibawah tertimpa Material (X6.3) & 7.8 \\
\hline \multirow{8}{*}{7} & \multirow{8}{*}{$\begin{array}{l}\text { Proses } \\
\text { Pengecoran (X7) }\end{array}$} & $\begin{array}{l}\text { Mata pekerja terkena adonan beton saat menuangkan adonan beton ready } \\
\text { mix ke cetakan) (X7.1) }\end{array}$ & 6.1 \\
\hline & & pekerja terjatuh dari ketinggian (X7.2) & 4.1 \\
\hline & & Pekerja terpeleset saat menahan/memindahkan concrete bucket (X7.3) & 5.7 \\
\hline & & Kabel Sling Putus (X7.4) & 6.7 \\
\hline & & Pekerja tertimpa concrete bucket $(X 7.5)$ & 4.2 \\
\hline & & Luka Gores (Akibat Concrete Vibrator) (X7.6) & 5.1 \\
\hline & & Lepasnya pipa trime $(X 7.7)$ & 4.7 \\
\hline & & Robohnya cetakan beton $(\mathrm{X} 7.8)$ & 6.1 \\
\hline \multirow{3}{*}{8} & \multirow{3}{*}{$\begin{array}{l}\text { Proses metoda } \\
\text { Predrainage }(X 8)\end{array}$} & Pekerja/Alat terseret aliran sungai (X8.1) & 3.6 \\
\hline & & Pekerja terjatuh dari ketingian & 4.4 \\
\hline & & Pekerja / Alat terjebak lumpur (X8.3) & 3.9 \\
\hline \multirow{5}{*}{9} & \multirow{5}{*}{$\begin{array}{l}\text { Proses } \\
\text { Pemasangan box } \\
\text { culvert (X9) }\end{array}$} & $\begin{array}{l}\text { Pekerja terluka akibat terkena kayu atau benda berbahaya di air (kayu, ranting } \\
\text { batu) (X9.1) }\end{array}$ & g, \\
\hline & & pekerja tersengat listrik (X9.2) & 5.3 \\
\hline & & Pekerja terkena material (X9.3) & 7.7 \\
\hline & & Gangguan Pernafasan akibat debu Proyek(X9.4) & 7.1 \\
\hline & & kebisingan saat penggunaan mesin di proyekl (X9.5) & 8.2 \\
\hline
\end{tabular}

Keterangan kategori risiko yaitu:

H (high): Risiko Besar, perlu perhatian khusus dari pihak manajemen.

M (medium): Risiko Sedang Risiko sedang, memerlukan tanggung jawab yang jelas dari manajemen.
L (Low): Risiko rendah, ditangani dengan prosedur yang rutin.

Tingkat atau level dari risiko merupakan alat yang sangat penting pada manajemen dalam pengambilan keputusan, karena melalui peringkat risiko pihak manajemen dapat 
menentukan prioritas dan penanganan ketika risiko tersebut terjadi. Pekerjaan yang memiliki Risiko menuju high adalah pada proses pemasangan box culvert yaitu bernilai 8.3, maka dapat diambil tindakan mengurangi Risiko terjadi kedepannya dengan solusi memperketat peraturan, mewajibkan pekerja memakai Alat Pelindung Diri (APD), dan melakukan survey risiko lingkungan atau Analisis Mengenai Dampak Lingkungan (AMDAL).

\section{Analisa Penilaian Risiko}

Dari hasil pengolahan data dan penggolongan matriks risiko berdasarkan standar AS/NZS 4360 diperoleh 45 variabel dengan level risiko sedang (Medium Risk), sedangkan untuk level risiko Rendah (Low Risk) diperoleh 2 variabel.

\section{Penetapan Sasaran K3}

Hal yang sangat penting dalam pembuatan program kerja K3 proyek adalah penetapan sasaran/target K3 proyek. Sasaran atau target K3 yang direncanakan akan menjadi tolak ukur keberhasilan pelaksanaan proyek pada aspek K3. Sasaran/target K3 pada proyek pembangunan Jaringan Daerah Irigasi Centro City Residence:

1. Zero Accident (kecelakaan fatal)

2. Menngkatkan kepedulian tentang K3 kepada seluruh pekerja

3. Pada pelaksanaan proyek tidak terjadi kecelakaan dan penyakit akibat kerja

4. Wajib menggunakan alat pelindung diri dan alat keamanan lainnya

5. Material ditumpuk rapi dan sesuai dengan jenisnya

6. Proyek bersih, rapi, dan sehat

7. Meningkatkan hasil produksi yang lebih baik

\section{Perencanaan Kegiatan K3}

Langkah berikutnya setelah penetapan sasaran/ target K3 adalah perencanaan kegiatan K3. Beberapa bentuk kegiatan K3 yang dapat dilakukan adalah sebagai berikut:

\section{Safety Induction}

Pengarahan/pendekatan kepada pekerja baru termasuk karyawan serta pengarahan tentang K3 dan ketertiban proyek. Kegiatan ini dilakukan pada awal pelaksanaan proyek atau setiap ada pekerja yang baru masuk.
2. Safety Talk

Penjelasan atau pengarahan singkat tentang K3 dan kondisi proyek kepada seluruh pekerja sebelum memulai pekerjaan. Hal ini penting agar pekerja mengetahui kondisi bahaya/risiko yang ada pada pekerjaan yang akan dihadapi.

3. Safety Meeting

Pertemuan/ rapat K3 diperlukan untuk meembahas masalah yang terjadi dan tindakan pencegahannya serta melaporkan kecelakaan yang terjadi dan langkah-langkah perbaikannya.

4. Safety Patrol

Inspeksi K3 atau safety patrol, dilakukan untuk pengawasan dan mengontrol kegiatan dilapangan apakah hasil sesuai dengan rencana atau tidak.

5. Training K3

Pelatihan K3 bagi karyawan dan petugas K3

6. Pemasangan rambu-rambu $\mathrm{K} 3$

Pemasangan rambu-rambu K3 sangat penting untuk memberikan peringatan bagi pekerja akan bahaya/risiko kecelakaan kerja selama berada dan bekerja di proyek. Rambu-rambu ini juga untuk mengingatkan karyawan dan pekerja agar menjaga keselamatan dan membuat lingkungan kerja menjadi bersih dan teratur.

\section{KESIMPULAN}

Berdasarkan hasil analisis manajemen risiko terhadap aspek keselamatan dan kesehatan kerja (K3) pada proyek pembangunan Jaringan DI. Kawasan Sawah Laweh Tarusan di Kab. Pesisir Selatan (Paket I) Lanjutan yang telah dilakukan, maka diberikan kesimpulan sebagai berikut:

1. Dari hasil penelitian teridentifikasi 45 variabel potensi risiko yang dapat terjadi pada proyek pembangunan Jaringan Daerah Irigasi Kawasan Sawah Laweh Tarusan di Kab. Pesisir Selatan (Paket) Lanjutan.

2. Dari hasil analisis penilaian terhadap risiko $\mathrm{K} 3$ diketahui level atau ranking menurut standar AS/NZS 4360 yaitu terdapat 45 risiko tergolong Medium Risk dan 2 risiko tergolong low Risk. 
3. Berdasarkan risiko yang telah diketahui maka strategi pengendalian risiko kecelakaan kerja adalah :

- Melakukan pendekatan dan pengarahan (Safety Induction) kepada pekerja baru, melakukan safety patrol K3, dan memasang rambu-rambu peringatan K3.

- Melakukan penyediaan alat pengaman diri (APD) dan memberi pelatihan kepada pekerja mengenai metodemetode penggunaan alat kerja dan metode-metode pelaksanaan pekerjaan.

- Menghilangkan risiko dengan cara melakukan penghentian kegiatan dan

\section{DAFTAR PUSTAKA}

Anonim. (2007). OHSAS 18001 : 2007, Occupational Health and Safety Management System, OHSAS Project Group, ISBN 978-0-580-61674-7

AS/NZS 4360. (2004). "3rd Edition The Australian and New Zealand Standard on Risk Management". Broadleaf Capital International Pty Ltd. NSW Australia

Hakim, A. R. (2020). Manajemen Risiko Terhadap Aspek Keselamatan dan Kesehatan Kerja Pada Proyek Konstruksi di Masa Pandemi Covid-19 (Studi Kasus: Pembangunan Gedung Rumah Sakit Umum Daerah Bayu Asih Purwakarta. Skripsi, Institut Teknologi Nasional Bandung.

ILO. (2013). Health and Safety in Work Place for Productivity. Geneva: International Labour Office.

Ramli, Soehatman. (2010). Pedoman Praktis Manajemen Risiko dalam Perspektif K3 OHS Risk Management. Jakarta: Dian Rakyat.

Sugiyono. (2012). Metode Penelitian Bisnis. Bandung: Alfabeta.

Trianty, Lidya. (2014). Potensi Bahaya K3 Pada Bagian Struktur dan Arsitektur Proyek Pembangunan Hotel The Regale Tahun 2013. Skripsi: Universitas Sumatera Utara

Boy, W., Erlindo, R., \& Fitrah, R. A. (2021). Faktor-Faktor Penyebab Keterlambatan Proyek Konstruksi Gedung Kuliah Pada penggantian bahan atau peralatan yang tidak layak pakai.

- Pengalihan risiko (risk transfer) dengan cara Setiap pekerja telah dilindungi dengan Jamsostek.

\section{UCAPAN TERIMA KASIH}

Ucapan terima kasih disampaikan kepada pihak-pihak yang telah membantu penelitian ini khususnya PT. Gunung Tabor yang telah membantu memberikan ijin dan pengambilan data dalam pelaksanaan penelitian ini.

Masa Pandemi Covid 19. Jurnal Rivet, 1(01), 57-64.

Sepang, B. A. W., Tjakra, J., Langi, J. E. C., \& Walangitan, D. R. O. (2013). Manajemen risiko keselamatan dan kesehatan kerja (K3) pada proyek pembangunan ruko Orlens Fashion Manado. Jurnal Sipil Statik, 1(4), pp. 282-288.

Rethyna, M. (2018). Analisis Risiko Keselamatan dan Kesehata Kerja (K3) pada Bangunan Gedung Bertingkat. IKRAITH TEKNOLOGI: Jurnal Sains \& Teknologi 2(1), pp. 20-24.

Septianingrum, W. U. (2012). Penilaian Risiko

Keselamatan Kerja Pada Proses Pemasangan Ring Kolom dan Bekisting di Ketinggian Pada Pembangunan Gedung XY oleh PT. X. Tugas Akhir. Universitas Indonesia.

Suma'mur, (1981). Keselamatan Kerja dan Pencegahan Kecelakaan. Jakarta: CV. Haji Mas Agung.

Pramana, Tony, 2011. Manajemen Risiko Bisnis. Penerbit Sinar Ilmu, Jakarta.

Wardhana, H. (2018). Manajemen Risiko K3 Pada Proyek Tower Transmisi (Studi Kasus: Proyek Pembangunan Jaringan Transmisi Tegangan Ekstra Tinggi $275 \mathrm{kV}$ Galang - Simangkuk). Tugas Akhir. Universitas Sumatera Utara.

Wibisana, D. A. (2016). Analisa Risiko Kecelakaan Kerja Proyek Bendungan Tugu Kabupaten Trenggalek Menggunakan Metode FMEA (Failure Mode And Effect Analysis) dan Metode Domino. Tugas Akhir. 